\title{
Materialistic Physics vs Spiritual Physics
}

\section{Tapan K Chaudhuri*, Tushar K Chowdhury, Tandra R Chaudhuri, Shree Taposh K Chowdhury, Shree Bulu R Chowdhury}

Chowdhury Spiritual Research Center, Hampton, Virginia, USA

*Corresponding Author: Tapan K Chaudhuri, Professor, Chowdhury Spiritual Research Center, Hampton, Virginia, USA.

Received: October 01, 2019; Published: October 05, 2019

DOI: $10.31080 /$ ASPS.2019.03.0413

The science of Physics basically deals with Energy and Matter. The Materialistic Physics deals with Materialistic Energy (e.g., electricity, magnetism, heat, light, nuclear energy etc.) and Non-living Matter.

Whereas the Spiritual Physics deals with Spiritual Energy (Electromagnetic Energy of the Human Mind) [1,2] and Living Matter (e.g., human being).

In the creation of matters, the Creator kept some similarities in the basic component of non-living matter and living matter - molecule, atom, subatomic particle and God particle.

\begin{tabular}{|l|c|c|}
\hline Molecule & Non-living Matter & Living Matter \\
\hline Atom & $\begin{array}{c}\text { Proton, Neutron } \\
\text { Electron }\end{array}$ & $\begin{array}{c}\text { Physical Body of the } \\
\text { Human being }\end{array}$ \\
\hline $\begin{array}{l}\text { Subatomic } \\
\text { Particle }\end{array}$ & Quarks & Mind \\
\hline God Particle & Higgs Boson & Soul \\
\hline
\end{tabular}

Table 1: Shows some similarities in the basic composition of non-living matter and living matter.

The human being is composed of three parts - Body, Mind and Soul. While the physical body of the human being comes under materialistic world, the mind and soul come under spiritual world. Just as the Earth possesses both gravitational forces and electromagnetic forces, the human mind possesses both gravitational forces and electromagnetic forces. It is these forces that create the bonding between the human beings - bonding between the husband and wife, bonding between the parents and children, bonding between other relatives, friends, non-relatives, and not yet known people thus creating loved ones, less loved ones, and not loved ones.
The fact that Spiritual Energy exists is proven by the beneficial effect of worship, prayer and meditation on the recovery from medical illnesses.

Based on the above facts, there exists the need for establishing a new branch of science called Spiritual Physics.

\section{Bibliography}

1. Chaudhuri TK., et al. Book - Physics of God, Universe, humankind and peace in family. Publisher - iUniverse, USA (2015).

2. Chaudhuri TK., et al. Book - Electromagnetic Energy of the Human Mind. Publisher - CreateSpace, USA (2017).

Volume 3 Issue 11 November 2019

(C) All rights are reserved by Tapan $\mathrm{K}$ Chaudhuri., et al. 